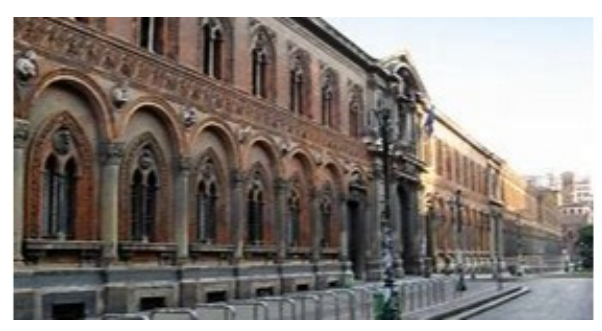

\title{
Prevention of MRONJ in non-oncological patients on antiresorptive drugs therapy: the pivotal role of past medical history.
}

Cristina Mirelli ${ }^{1}$, Andrea De Filippis ${ }^{1}$, Sara Pederielli, Cristina Dall'Agnola ${ }^{1}$, Sonia Marino ${ }^{1}$, Luca Bartorelli ${ }^{1}$

1 University of Milan

Funding: The author(s) received no specific funding for this work.

Potential competing interests: The author(s) declared that no potential competing interests exist.

\section{Abstract}

A proactive prevention attitude is the most appropriate choice for ensuring healthy oral conditions in patients on antiresorptive therapy. For this reason an assistance service called Progetto Bifosfonati was set up at the Ospedale Maggiore Policlinico of Milan (IRCCS Fondazione CàGranda) for secondary and tertiary prevention of MRONJ. Since 2006 the Project has admitted patients taking or approaching a therapy with antiresorptive drugs (ARDs), coming from various backgrounds: some were sent from hospital wards, some by general practitioners in private clinics, some came spontaneously. Clinical examination is based on standardized clinical records that include details of their medical history. Below we describe cases of osteonecrosis in patients with osteoporosis, underlining their clinical history and comorbidities.

\section{Background}

Medication Related Osteonecrosis of the Jaw (MRONJ) is a rare adverse effect of ARDs mainly occurring in oncological patients (1). It is diagnosed when a radiographic osteolytic lesion or a bone exposure in the oral cavity persists for more than 8 weeks (2). It has already been demonstrated that periodontal disease and dental extractions are main factors in contributing to the appearance of MRONJ. During the activity of the PROGETTO BIFOSFONATI, MRONJ was reported both in patients with cancer and in patients taking bisphosphonates in order to reduce the risk of fractures due to osteoporosis. According to literature, the latter would be an exceptionally rare occurrence. Osteonecrosis cases in osteoporotic patients are reported by describing their medical history, possible secondary causes and triggers. 


\section{Materials and Methods}

A standardized clinical record form is completed upon first examination of every patient participating in the PROGETTO BIFOSFONATI. Information concerning age, gender, smoking, previous HBV/HCV/HIV infection, bleeding disorders, previous or ongoing breast tumor/ prostate tumor/ chronic myeloid leukemia, bone metastasis, pharmacological anamnesis, previous and current ARD intake, dental pathologies, and dental treatments was recorded. We selected cases of patients taking ARDS for osteoporosis who developed MRONJ either during the program or before participating in it. None of these patients was affected by any type of cancer or was younger than 35 . Finally, we studied the circumstances and causes of each necrotic event and evaluated the known secondary factors associated with MRONJ.

\section{Results}

Over a period of 14 years MRONJ developed in 8 patients with osteoporosis only. Table 1 includes data from their clinical history. Age ranged from 58 to 99. Patients were on ARD therapy (6 with Alendronate, 1 Risedronate, 1 with Clodronate). One of them discontinued the intake of ARD for six months, one other switched from subcutaneous administration to oral. 4 of them had continued the therapy for $>10$ years, 2 of them for $>5$ years, 2 for $<5$ years. 3 of them were suffering from autoimmune diseases, 2 from hypertension, one had been infected with HCV. The triggering cause for the necrosis was identified as a tooth extraction in 4 cases, as a periodontal abscess in 1, while in 3 of the cases it still remains unknown.

\section{Table 1.}

\begin{tabular}{|c|c|c|c|c|c|c|c|c|c|}
\hline Sex & Age & ARD 1 & Administration & ARD 2 & Administration & $\begin{array}{l}\text { Beginning } \\
\text { year }\end{array}$ & $\begin{array}{l}\text { Duration in } \\
\text { years }\end{array}$ & Other pathologies & $\begin{array}{l}\text { Triggering event } \\
\text { necrosis }\end{array}$ \\
\hline $\mathrm{F}$ & 73 & Risedronate & Os & none & & 2006 & 2 & hypertension & periodontal abscess \\
\hline $\mathrm{F}$ & 82 & Alendronate & Os & none & & 1997 & 16 & $\begin{array}{l}\text { autoimmune } \\
\text { diseases }\end{array}$ & unknown \\
\hline $\mathrm{F}$ & 74 & Alendronate & Os & Alendronate & Os & 2000 & 11 & $\begin{array}{l}\text { autoimmune } \\
\text { diseases }\end{array}$ & tooth extraction \\
\hline $\mathrm{F}$ & & Alendronate & Os & none & & 2007 & 4 & $\mathrm{HCV}$ & tooth extraction \\
\hline $\mathrm{F}$ & 71 & Alendronate & Os & none & & 2012 & 7 & & unknown \\
\hline $\mathrm{F}$ & 58 & Alendronate & Os & none & & 2003 & 6 & $\begin{array}{l}\text { autoimmune } \\
\text { diseases }\end{array}$ & tooth extraction \\
\hline $\mathrm{F}$ & 91 & Clodronate & Im & Alendronate & Os & 1995 & 26 & hypertension & unknown \\
\hline M & 77 & alendronate & Os & none & & 2005 & 11 & & tooth extraction \\
\hline
\end{tabular}

\section{Conclusions}

These facts underline that the occurrence of MRONJ following dental treatment in osteoporotic patients is a considerable phenomenon that may grow in the near future. A full understanding of the risks of MRONJ in osteoporotic patients and a careful evaluation of their medical history by dentists, especially concerning secondary risk factors, is crucial in performing effective prevention. In order to treat the patient in the best possible way, a multidisciplinary effort from the dentist and the specialist who evaluates bone metabolism may be required. Before starting antiresorptive therapy, patients should undergo a dental examination. Over time, ARD and other therapies need to be reevaluated in order to avoid the known side effects that appear following a prolonged intake. With this aim of prevention, great importance should be given to multidisciplinary services that support clinicians in the management of patients on ARDs and who are exposed to 
secondary risk factors for development of osteonecrosis. The Progetto Bifosfonati has long embraced this line of behaviour, collaborating with care givers or inviting patients to a therapeutic revaluation, supervising the application of Siomms guidelines (3).

\section{References}

1. Advisory Task Force on Bisphosphonate-Related Ostenonecrosis of the Jaws, American Association of Oral and Maxillofacial Surgeons. American Association of Oral and Maxillofacial Surgeons position paper onbisphosphonaterelated osteonecrosis of the jaws. J Oral Maxillofa Surg 2007;65(3):369-376. doi:10.1016/j.joms.2006.11.003

2. Campisi G; Bedogni A, Fusco V. Raccomandazioni clinico-terapeutiche sull'osteonecrosi delle ossa mascellari (ONJ) farmaco-relata e sua prevenzione. Palermo University Press 2020. doi:10.19229/9788855091480/01062020

3. Rossini M, Adami S, Bertoldo F, Diacinti D, Gatti D, Giannini S, Giusti A, Malavolta N, Minisola S, Osella G, Pedrazzoni M, Sinigaglia L, Viapiana O, Isaia GC. Guidelines for the diagnosis, prevention and management of osteoporosis. Reumatismo. 2016 Jun 23;68(1):1-39. doi: 10.4081/reumatismo.2016.870. PMID: 27339372. 